\title{
MAKNA BAHASA TUBUH: SUATU KAJIAN LINTAS BUDAYA
}

\author{
I Nengah Mileh \\ Universitas Warmadewa \\ milehmenuri@gmail.com
}

\begin{abstract}
ABSTRAK
Penelitian ini berjudul "Makna Bahasa Tubuh: Suatu Kajian Lintas Budaya". Pengungkapan pikiran dan perasaan melalui bahasa menggunakan kata sebagai sarananya. Di samping itu, ada pula bahasa yang tidak menggunakan kata sebagai sarana pengungkapannya, bahasa semacam ini disebut bahasa tubuh. Bahasa tubuh menggunakan gerakan tubuh sebagai sarana pengungkapannya. Penelitian ini bertujuan menemukan persamaan dan perbedaan bahasa tubuh dari dua negara, yaitu Indonesia dan Jepang. Metode observasi dan teknik catat digunakan dalam pengumpulan data, metode deskriptif digunakan untuk menganalisis data dibantu dengan teknik induktif atau teknik deduktif, sedangkan penyajian hasil analisis digunakan metode informal dan metode formal. Dalam penelitian ini ditemukan beberapa persamaan dan perbedaan makna bahasa tubuh dari dua negara yang berbeda, yakni negara Indonesia dan negara Jepang.
\end{abstract}

Kata kunci: Bahasa; budaya; makna

\section{ABSTRACT}

This study is entitled "The Meaning of Body Language: A Cross-Cultural Study". In expressing thoughts and feelings through language uses words as a means. In addition, there are also languages that do not use words as a means of expression, this kind of language is called body language. Body language uses body movements as a means of expression. This study aims to find similarities and differences in body language from two countries, namely Indonesia and Japan. Observation methods and note techniques are used in data collection, descriptive methods are used to analyze data assisted by inductive or deductive techniques, while the presentation of the results of the analysis is using informal and formal methods. This study found several similarities and differences in the meaning of body language from two different countries, namely Indonesia and Japan.

Keywords: language; culture; meaning

\section{PENDAHULUAN}

Manusia adalah mahluk sosial yang sangat bergantung pada orang lain. Kehidupan seseorang sangat bergantung kepada pihak lain. Manusia tidak dapat hidup tanpa kehadiran orang dalam masyarakat (Mustakim, 1994: 1). Sebagai mahluk sosial, manusia terdorong untuk bergaul dengan manusia lain. Manusia memiliki kepentingan untuk menyampaikan pikirannya, mengekspresikan dirinya, menyatakan pendapat, dan untuk memengaruhi orang lain. Sehubungan dengan itu, bahasa menjadi amat penting dalam kehidupan manusia.
Kepentingan terhadap bahasa itu hampir meliputi segala bidang kehidupan. Segala sesuatu yang dialami dan dirasakan oleh manusia hanya dapat diungkapkan atau disampaikan dengan wahana bahasa, baik melalui bahasa lisan atau tulisan, maupun bahasa isyarat.

Kita tidak bisa membayangkan apa yang akan terjadi bila manusia tidak memiliki bahasa. Semua kegiatan yang dilakukan oleh manusia tidak dapat terlaksana dengan baik, jika tidak mamakai bahasa sebagai sarananya. 
Seorang penutur dapat berkomunikasi dengan baik, bila mampu mengemas gagasan dengan menggunakan bahasa. Hal-hal penting yang perlu diperhatikan ketika berkomunikasi, yaitu sebagai berikut: (1) memperhatikan situasi dengan baik di mana peritiwa wicara itu terjadi, (2) siapa yang ikut terlibat dalam peristiwa komunikasi tersebut, (3) apa tujuan yang ingin dicapai dari komunikasi tersebut, (4) siapa lawan bicara pada saat komunikasi itu berlangsung, (5) Materi apa yang menjadi kunci/pokok pembahasan, (6) sarana apa saja yang dapat menunjang kelancaran dalam berkomunikasi, (7) norma atau kaidah kebahasaan yang harus diikuti oleh pembicara, dan (8) ragam bahasa apa yang sesuai dengan situasi komunikasi tersebut (Pranowo, 2014: 176).

Komunikasi dapat berjalan lancar, jika masing-masing orang berusaha dengan strateginya masing-masing. Penutur berusaha agar apa yang disampaikan dapat diterima dengan baik oleh lawan bicaranya. Penutur berusaha menggunakan kalimat, pilihan kata, gaya bahasa, ragam yang benar dengan harapan lawan bicara dapat dengan mudah menangkap isi pembicaraan itu. Hal ini penting dilakukan, karena prinsip berbahasa adalah komunikati.

Gambaran di atas memperlihatkan bahwa bahasa menjadi media komunikasi yang sangat penting dalam kehidupan. Oleh karena itu, peran bahasa dalam masyarakat menjadi sangat vital. Dalam rangka menjalin kerjasama antarsesama manusia dalam lingkungan bermasyarakat, sarana bahasalah yang paling efektif digunakan.

Bahasa, dapat juga digunakan sebagai sarana bertukar pikiran, berdialog, dan menyampaikan pikiran atau perasaan kepada orang lain. Dengan bahasa pula, orang dapat manusia dapat mempelajari segala sesuatu yang dialami dalam kehidupan ini. Kita dapat mewarisi kebudayaan suatu bangsa dengan bantuan sarana berupa bahasa. Tidak hanya mewarisi kebudayaan yang dapat kita lakukan, tetapi juga dapat mewariskan kebudayaan itu ke generasi berikutnya.

Jadi, dapat dikatakan bahwa bahasa merupakan alat utama untuk berkomunikasi. Bahasa dari segi sarananya dapat dipilah menjadi dua, yaitu bahasa lisan dan bahasa tulisan. Baik bahasa lisan maupun bahasa tulisan menggunakan kata sebagai sarana pengungkapan. Di samping itu, ada pula bahasa yang tidak menggunakan kata sebagai sarana pengungkapannya, bahasa itu termasuk ke dalam bahasa isyarat.

Alat komunikasi nonlinguistik itu bervariasi sesuai dengan budayanya, salah satunya adalah komunikasi dengan bahasa/sistem isyarat. Bahasa isyarat ini menjadi bidang kajian kinesics (Alwasilah, 1985: 14). Kinesics membahasas, antara lain: gerakan mata, perubahan ekspresi muka, perubahan posisi kaki, dan gerakan anggota tubuh yang melibatkan tangan dan bahu. Bahasa jenis inilah yang dimaksud dengan bahasa tubuh, yaitu bahasa yang menggunakan gerakan anggota tubuh sebagai sarana pengungkapan pikiran atau perasaan. Setiap gerakan anggota tubuh mempunyai makna sendiri-sendiri.

Komunikasi antarmanusia di dunia lewat gerakan anggota tubuh adalah komunikasi antarbudaya. Artinya, komunikasi ini hanya dapat dipahami bila kita memahami budaya masing-masing bangsa. Budaya Indonesia akan berbeda dengan budaya bangsa lainnya seperti budaya Jepang, budaya Australia, budaya India dan lain-lain. Misalnya, orang India yang menggerakkan anggota tubuhnya berupa anggukan kepala mengandung makna tidak setuju sedangkan bagi Indonesia gerakan itu bermakna setuju. Jadi, terjadi perbedaan makna bahasa tubuh antara orang India dengan orang Indonesia.

Kebudayaan bangsa-bangsa di dunia di samping memiliki perbedaan-perbedaan seperti disebutkan di atas, juga memiliki persamaanpersamaan. Ini dimungkinkan karena kebudayaan itu juga bersifat universal. Keuniversalannya ini ditandai oleh adanya kesamaan-kesamaan makna bahasa tubuh dari berbagai bangsa. Dalam tulisan ini hanya diuraikan mengenai perbedaan dan persamaan makna bahasa tubuh dua Negara, yaitu Indonesia dan Jepang.

Berlandaskan paparan pada latar belakang di atas, dapat dirumuskan beberapa permasalahan. Beberapa permasalahan tersebut dapat dirumuskan seperti berikut ini.

1. Apakah makna bahasa tubuh dari masing-masing bangsa, yaitu bangsa Indonesia dan bangsa Jepang? 
2. Apakah persamaan dan perbedaan makna bahasa tubuh dari masingmasing bangsa tersebut?

\section{METODE}

Dalam konteks penelitian ini, ada tiga hal yang wajib dipakai dalam penelitian ini, yaitu tahapan pengumpulan dan tahapan analisis data serta tahapan yang terakhir adalah tahapan penyajian hasil analisis. Ketiga tahapan ini akan dibahas seperti di bawah ini.

\section{Metode Pengumpulan Data}

Pengumpulan data dalam penelitian ini menggunakan metode observasi/simak (Sudaryanto, 1993: 133) dibantu dengan kegiatan berupa pencatatan data secara maksimal. Kegiatan ini dilakukan secara langsung mencermati keterangan-keterangan yang diberikan oleh informan baik keterangan berupa kata-kata maupun gerakan-gerakan anggota tubuh yang dapat lebih memperjelas keterangan-keterangan yang berupa kata-kata tadi. Semua keterangan dan penjelasan tadi penulis catat untuk menghindari ketumpangtindihan data dan kelupaan dalam pengingatan data.

\section{Metode Analisis Data}

Pada tahapan ini, peneliti melakukan analisis dengan menggunakan metode deskriptif. Metode ini adalah sebuah cara mengolah data seobjektif-objektifnya (sesuai dengan data yang ada di lapangan). Untuk memeroleh hasil analisis yang maksimal, metode yang dipakai adalah metode deskriptif komparatif, yaitu suatu cara analisis yang objektif dengan cara membandingkan dua sumber yang berbeda.

\section{Metode Penyajian Hasil}

Tahapan terakhir dari penelitian ini adalah penyajian hasil penelitian. Penyajian hasil dalam penelitian ini memakai metode penyajian informal, yaitu suatu cara perumusan dengan menggunakan kata kata biasa (Sudaryanto, 1993: 145). Teknik penyajian hasil yang digunakan dalam rangka menjamin kesistematisan tulisan adalah teknik induktif, yakni suatu cara bernalar dengan lebih awal menyampaikan sesuatu yang khusus selanjutnya dibuatkan simpulan yang bermakna umum (Hadi, 1982: 43-44).

\section{PEMBAHASAN \\ Makna Bahasa Tubuh}

Komunikasi yang terjadi dalam kehidupan di masyarakat, dipilah menjadi dua, yaitu komunikasi dengan bahasa dan komunikasi dengan nonbahasa. Gerakan anggota tubuh sebagai sarana komunikasi yang sering digunakan oleh manusia dalam kesehariannya dapat digolongkan sebagai komunikasi nonverbal.

Komunikasi verbal dapat dilakukan jika antara penutur dan pendengar menggunakan bahasa, yang sama-sama dipahami oleh kedua belah pihak. Berbeda halnya, jika kita berkomunisi dengan menggunakan bahasa tubuh atau bahasa isyarat. Penggunaan bahasa tubuh/isyarat dalam berkomunikasi memerlukan pemahaman yang lebih kompleks, karena gerakan anggota tubuh di suatu daerah atau bangsa kadang-kadang memiliki makna yang sama atau mungkin juga memiliki makna yang berbeda. Makna bahasa tubuh di suatu daerah/bangsa dominan ditetapkan melalui kesepakatan pendukung budaya tersebut, atau dengan kata lain dilakukan secara konvensional.

Semiotika, bidang ilmu yang membicarakan mengenai tanda dan semua yang berkaitan dengan tanda tersebut. Secara rinci bidang ilmu ini membicarakan hal-hal yang berkaitan dengan fungsi, cara, pengiriman dan penerimaanya tanda-tanda itu oleh penggunanya (Sujiman, 1996). Ilmu tentang tanda, yang berfokus pada penggolongan hubungan dengan tanda-tanda lain, dan caranya bekerja sama dalam menjalankan fungsinya disebut sintaksis semiotik. Bila kajiannya menekankan pada hubungan antara tanda dengan pengirim dan penerimanya, maka dogolongkan ke dalama pragmatik semiotik.

Hubungan antara tanda dengan acuannya memiliki tiga hubungan, yaitu hubungan antara tanda dengan acuannya yang menyatakan hubungan kemiripan disebut ikon. Misalnya peta geografis, potret/foto. Hubungan yang dapat meniimbullkan kedekatan eksistensi disebut indeks. Contohnya pemunjuk jalan atau penunjuk angin. Hubungan yang terbentuk secara konvensional disebut dengan symbol. 
Contohnya, anggukan kepala yang bermakna setuju (Sujiman, 1996: 8-9).

Gerakan anggota tubuh sebagai bentuk komunikasi nonverbal merupakan produk budaya. Sebagai produk budaya, bahasa tubuh juga memiliki banyak persamaan dengan bahasa. Kedua bentuk komunikasi ini, dapat dipelajari dan diwariskan kepada gerasi yang akan sebagai warisan budaya. Misalnya kata stop yang bermakna 'berhenti', memiliki makna yang sama dengan bahasa tubuh "lengan diangkat lurus ke udara dengan telapak tangan menghadap ke muka".

Pada umumnya nonlinguisti, termasuk di dalamnya bahasa tubuh merupakan bagian dari budaya suatu daerah atau bangsa. Di Indonesia untuk menyatakan seseorang itu gila atau sinting biasanya menggunakan jari telunjuk yang diletakkan pada dahi dengan posisi miring. Demikian pula, jika kita ingin memberitahukan kepada orang lain agar tidak ribut, biasanya kita menggunakan jari telunjuk yang diletakkan pada bibir. Kedua bahasa tubuh itu sudah menjadi bagian dari budaya leluhur kita.

Simbol-simbol nonverbal dan hal yang ditimbulkan oleh simbol/lambang tersebut termasuk bagian dari suatu budaya yang telah diwariskan oleh pendahulu kita. Setiap simbol yang ada pada nonverbal memiliki makna sesuai dengan kesepakatan antara pengguna simbol/lambang itu. Budaya memengaruhi prilaku kita dalam berkomunikasi, baik secara linguistik maupun nonlinguistik.

Budaya menjadi sumber inspirasi dari suatu kelompok orang dalam kaitan untuk memahami, menginterprestasi, dan memroduksi simbol/lambang dengan cara tertentu. Dengan demikian, dapat disebutkan bahwa budaya merupakan kebiasaan-kebiasaan yang hidup dan berkembang di suatu daerah/bangsa. Kebiasaan ini memberikan semacam efesiensi kepada dunia di mana segala sesuatu dapat merupakan tanda.

Perbedaan-perbedaan dalam kebiasaan semiotik menentukan garis demarkasi antara suatu kebudayaan dengan kebudayaankebudayan lainnya. Jika tidak menyadari perbedaan-perbedaan tersebut, maka akan terjadi kesalahpahaman yang cukup serius. Tanda selalu terikat dengan budaya, itu berarti bahwa cara terbaik untuk menjadi akrab dengan budaya tertentu adalah dengan cara menelusuri semiotic yang sedang berlaku dalam budaya itu.

Makna bahasa tubuh suatu bangsa sangat berkaitan dengan budaya bangsa yang bersangkutan. Di bawah ini disajikan makna bahasa tubuh dari dua bangsa yang berbeda, yaitu Indonesia dan Jepang.

1. Makna Bahasa Tubuh Bangsa Indonesia

Bagi orang Indonesia ada beberapa gerakan anggota tubuh yang memiliki makna tersendiri. Gerakan-gerakan yang dimaksud adalah sebagai berikut.

Tabel 1. Makna Bahasa Tubuh Bangsa Indonesia

\begin{tabular}{|c|c|c|}
\hline No & $\begin{array}{c}\text { Gerakan Anggota } \\
\text { Tubuh }\end{array}$ & Makna \\
\hline 1 & $\begin{array}{l}\text { Tangan kanan } \\
\text { didekapkan ke dada }\end{array}$ & 'saya' \\
\hline 2 & $\begin{array}{l}\text { Tangan kanan } \\
\text { dilambai-lambaikan ke } \\
\text { atas }\end{array}$ & $\begin{array}{l}\text { 'selamat } \\
\text { tinggal' }\end{array}$ \\
\hline 3 & $\begin{array}{l}\text { Tangan kanan } \\
\text { diluruskan atau } \\
\text { dilekukkan sedikit } \\
\text { dengan jari-jari } \\
\text { digerakkan ke atas atau } \\
\text { ke bawah. Jika } \\
\text { gerakannya ke atas } \\
\text { berbeda dengan } \\
\text { gerakannya ke bawah }\end{array}$ & $\begin{array}{l}\text { 'ke sana } \\
\text { atau 'ke } \\
\text { mari' }\end{array}$ \\
\hline 4 & $\begin{array}{l}\text { Tangan kanan } \\
\text { diluruskan ke muka } \\
\text { atau ke samping dengan } \\
\text { gerakan jari-jari ke atas } \\
\text { atau ke bawah }\end{array}$ & 'stop' \\
\hline 5 & $\begin{array}{l}\text { Kepala diangguk- } \\
\text { anggukan }\end{array}$ & $\begin{array}{l}\text { 'ya' atau } \\
\text { 'setuju' }\end{array}$ \\
\hline 6 & $\begin{array}{l}\text { Kepala digeleng- } \\
\text { gelengkan }\end{array}$ & 'tidak' \\
\hline 7 & $\begin{array}{l}\text { Telunjuk diluruskan } \\
\text { dan dilekatkan pada } \\
\text { bibir atau hidung }\end{array}$ & 'diam’ \\
\hline 8 & $\begin{array}{l}\text { Ibu jari diluruskan dan } \\
\text { menghadap ke atas }\end{array}$ & $\begin{array}{l}\text { 'baik atau } \\
\text { bagus' }\end{array}$ \\
\hline 9 & $\begin{array}{l}\text { Kepala sedikit } \\
\text { digerakan ke bawah }\end{array}$ & 'hormat \\
\hline 10 & Mata melotot & 'marah' \\
\hline 11 & $\begin{array}{l}\text { Tangan kanan diangkat } \\
\text { dengan telunjuk } \\
\text { diluruskan }\end{array}$ & $\begin{array}{l}\text { 'saya' } \\
\text { (untuk } \\
\text { bertanya }\end{array}$ \\
\hline
\end{tabular}


atau

menangapi)

2. Makna Bahasa Tubuh Bangsa Jepang

Seperti orang Indonesia orang Jepang pun memiliki beberapa gerakan anggota tubuh yang bila ditelusuri mempunyai makna yang berbeda-beda. Makna masingmasing gerakannya ini tercermin seperti di bawah ini.

Tabel 2. Makna Bahasa Tubuh Bangsa Jepang

\begin{tabular}{|c|c|c|}
\hline No & $\begin{array}{c}\text { Gerakan Anggota } \\
\text { Tubuh }\end{array}$ & Makna \\
\hline 1 & $\begin{array}{l}\text { Telunjuk tangan } \\
\text { kanan diluruskan dan } \\
\text { dilekatkan ke hidung }\end{array}$ & 'saya' \\
\hline 2 & $\begin{array}{l}\text { Tangan kanan lurus } \\
\text { ke atas dan dilambai- } \\
\text { lambaikan }\end{array}$ & $\begin{array}{l}\text { 'selamat } \\
\text { jalan' }\end{array}$ \\
\hline 3 & $\begin{array}{l}\text { Tangan kanan } \\
\text { diluruskan dengan } \\
\text { tanpa gerakan jari-jari } \\
\text { tangan }\end{array}$ & 'stop' \\
\hline 4 & $\begin{array}{l}\text { Ibu jari dan telunjuk } \\
\text { dilengkungkan } \\
\text { sehingga membentuk } \\
\text { huruf O }\end{array}$ & $\begin{array}{l}\text { 'bagus','betul } \\
\text { ', 'baik' }\end{array}$ \\
\hline 5 & $\begin{array}{l}\text { Kedua telunjuk } \\
\text { disilang }\end{array}$ & 'tidak baik' \\
\hline 6 & $\begin{array}{l}\text { Telunjuk diputar- } \\
\text { putar dekat telinga }\end{array}$ & $\begin{array}{l}\text { 'sinting' atau } \\
\text { 'gila' }\end{array}$ \\
\hline 7 & Anggukan kepala & 'setuju' \\
\hline 8 & Badan dibungkukkan & 'setuju' \\
\hline 9 & $\begin{array}{l}\text { Tangan kanan } \\
\text { diangkat ke atas } \\
\text { dengan telapak tangan } \\
\text { diluruskan }\end{array}$ & $\begin{array}{l}\text { 'saya' (untuk } \\
\text { bertanya atau } \\
\text { menanggapi) }\end{array}$ \\
\hline
\end{tabular}

\section{Persamaan dan Perbedaan Makna Bahasa Tubuh}

Persamaan dan perbedaan makna bahasa tubuh pasti akan terjadi. Persamaan makna bahasa tubuh terjadi karena ada hal-hal budaya tertentu yang bersifat universal sedangkan perbedaan muncul terjadi karena masingmasing bangsa memiliki budaya dan interprestasi sendiri-sendiri terhadap budayanya yang dilakukan secara konvensional.
1. Persamaan Makna Bahasa Tubuh

Berbicara mengenai persamaan makna bahasa tubuh, ini berarti yang dibahas adalah gerakan-gerakan tubuh yang dilakukan oleh berbagai bangsa di dunia memiliki kesamaan atau kemiripan gerakan dan sekaligus memiliki kesamaan makna atau arti. Munculnya gerakan anggota tubuh yang sama dengan makna yang sama atau mirip disebabkan oleh sifat budaya yang universal.

Budaya merupakan cerminan pola hidup suatu daerah atau masyarakat tertentu. Budaya sangat kompleks, abstrak, dan luas, sehingga dalam berprilaku komunikatif aspek budaya ikut serta memengaruhi. Aspek-aspek budaya suatu daerah sering sekali meliputi dan memengaruhi kegiatan yang dilakukan di daerah tersebut.

Yang dimaksud dengan budaya yang bersifat universal adalah budaya yang dimiliki, dipahami, dan dilaksanakan oleh masyarakat dunia dalam kehidupannya. Beberapa hal yang merupakan budaya universal antara lain: kekerabatan, peran gender, makna bahasa tubuh, dan sebagainya.

Ilmu-ilmu sosial telah lama membahas tentang hal-hal yang berkaitan dengan budaya universal. Elemen-elemen umum yang ada dalam kehidupan manusia dapat menjadi budaya universal, tanpa melihat sejarah dan geografisnya.

Persamaan yang paling menonjol di antara bangsa Indonesia dengan bangsa Jepang adalah mengenai gerakan anggota tubuh serta makna yang dikandungnya. Kedua bangsa ini, dalam penggunaan tangan kanan yang paling dominan. Tentu, tidaklah sopan bila kita memanggil seseorang atau menunjuk seseorang dengan menggerakkan tangan kiri. Di sinilah letak persamaannya (keuniversalan).

Persamaan yang lainnya adalah adanya lambaian tangan kanan yang bermakna 'selamat tinggal'. Di samping itu, anggukan kepala maknanya juga sama, yaitu bermakna 'ya' atau 'setuju'. Satu lagi yang maknanya persis sama, yaitu ketika telunjuk diluruskan dan dilekatkan pada bibir bermakna 'diam'. 
Gerakan tangan yang menandakan stop atau berhenti antara orang Indonesia dengan orang Jepang ada juga persamaannya, yaitu sama-sama tangan kanan diluruskan. Bedanya, bagi orang Indonesia tangan kanan diluruskan disertai dengan gerakan jari-jari tangan ke atas atau ke bawah, sedangkan bagi orang jepang tanpa disertai gerakan jari-jari tangan.

2. Perbedaan Makna Bahasa Tubuh

Kata perbedaan berasal dari kata beda dan konfiks per-an. Kata beda mempunyai makna 'sesuatu yang berlainan (tidak sama) antara benda yang satu dengan benda yang lain: ketidaksamaan' (Pusat Pembinaan dan Pengembangan Bahasa Departemen Pendidikan Kebudayaan, 1983).

Dalam konteks ini berarti ada gerakangerakan anggota tubuh yang memiliki perbedaan antara satu bangsa dengan bangsa lain. Perbedaan tidak saja terjadi dalam gerakan anggota tubuh, tetapi juga berbeda dari makna yang ditimbulkan. Perbedaan bahasa tubuh dan makna yang ditimbulkan tidak lepas dari perbedaan budaya yang khas di masing-masing negara dan kesepakan mereka terhadap sesuatu secara konvensional.

Berdasarkan penelitian ini, ditemukan beberapa perbedaan makna bahasa tubuh di antara dua bangsa, yaitu Indonesia dan Jepang. Perbedaan itu dapat diperhatikan pada uraian berikut ini.

Apabila ibu jari dan telunjuk dilengkungkan sehingga menyerupai huruf $\mathrm{O}$ menurut orang jepang maknanya adalah 'baik' atau 'bagus', sedangkan bagi orang Indonesia sedikit berbeda. Perbedaannya adalah hanya ibu jari saja yang diluruskan bukan dilengkungkan dengan telunjuk seperti pada orang jepang.

Gerakan anggota tubuh berupa telunjuk diputar-putar dekat telinga menurut orang jepang memiliki makna 'sinting' atau 'gila'. Namun bagi orang Indonesia untuk menyatakan sinting atau gila bukan seperti orang jepang tetapi dengan cara memerengkan telunjuk pada dahi.

Untuk menyatakan makna baik bagi orang Indonesia adalah dengan cara meluruskan ibu jari dan tegak ke atas. Berbeda pula bagi orang Jepang, mereka akan menyilangkan kedua telunjuk sebagai tanda atau makna tidak baik.

Menurut orang Jepang, jika tangan kanan diangkat ke atas dengan telapak tangan diluruskan memiliki makna 'saya'. Makna 'saya' ini digunakan bila seseorang ingin bertanya atau menanggapi pembicaraan seseorang. Berbeda bagi orang Indonesia, yang diluruskan hanya telunjuk saja, sekalipun tangan kanannya sama-sama diangkat ke atas.

\section{SIMPULAN}

Bertitik tolak dari hasil pembahasan pada Bab III di atas, dibuat gambaran ringkas dalam bentuk simpulan. Secara rinci simpulan itu diuraikan sebagai berikut.

Pertama, Setiap bangsa memiliki gerakan anggota tubuh yang bermakna. Gerakan anggota tubuh yang bermakna itu, disebut bahasa tubuh, yaitu bahasa yang menggunakan gerakan anggota tubuh sebagai sarana pengungkapan pikiran atau perasaan. Oleh karena itu, gerakan anggota tubuh ini termasuk bahasa nonverbal.

Kedua, Setiap gerakan anggota tubuh itu mempunyai makna tersendiri. Makna gerakan anggota tubuh ini, bagi masing-masing bangsa di dunia ada yang sama. Beberapa contoh makna bahasa tubuh yang sama antara lain: lambaian tangan kanan yang bermakna 'selamat tinggal'. Di samping itu, anggukan kepala maknanya juga sama, yaitu bermakna 'ya' atau 'setuju'. Satu lagi yang maknanya persis sama, yaitu ketika telunjuk diluruskan dan dilekatkan pada bibir bermakna 'diam'. Di samping adanya persamaan makna bahasa tubuh, ada juga perbedaan makna bahasa tubuh yang ditemukan. Perbedaan makna bahasa tubuh tersebut, antara lain: telunjuk diputarputar dekat telinga menurut orang jepang memiliki makna 'sinting' atau 'gila'. Namun, bagi orang Indonesia untuk menyatakan sinting atau gila bukan seperti orang jepang tetapi dengan cara memerengkan telunjuk pada dahi. Contoh lain yang menyatakan berbeda, yaitu tangan kanan diangkat ke atas dengan telapak tangan diluruskan memiliki makna 'saya'. Makna 'saya' ini digunakan bila seseorang ingin bertanya atau menanggapi pembicaraan 
seseorang. Berbeda bagi orang Indonesia, yang diluruskan hanya telunjuk saja, sekalipun tangan kanannya sama-sama diangkat ke atas.

\section{DAFTAR PUSTAKA}

Alwasilah, A. C. (1985). Sosiologi Bahasa. Angkasa.

Hadi, S. (1982). Metodologi Researsh 1. Yayasan Penerbit Fakultas Psikologi UGM.

Mustakim. (1994). Membina Kemampuan Berbahasa, Panduan ke arah kemarihan
Berbahasa. PT Gramedia.

Pranowo. (2014). Teori Belajar Bahasa, untuk Guru dan Mahasiswa Jurusan Bahasa. Pustaka Belajar.

Pusat Pembinaan dan Pengembangan Bahasa Departemen Pendidikan Kebudayaan. (1983). Kamus Bahasa Indonesia.

Sudaryanto. (1993). Metode dan aneka teknik analisis bahasa. Duta Wacana University Press.

Sujiman, P. (1996). Serba-serbi Semiotika. PT Gramedia Pustaka Utama 